\title{
RUANG KEBUGARAN DI PLUIT
}

\author{
Jonea Kane Darmanto ${ }^{1)}$, Nina Carina ${ }^{2)}$ \\ 1) Program Studi S1 Arsitektur, Fakultas Teknik, Universitas Tarumanagara, Joneakane@hotmail.com \\ 2) Program Studi S1 Arsitektur, Fakultas Teknik, Universitas Tarumanagara, ninac@ft.untar.ac.id
}

\begin{abstract}
Abstrak
Perkotaan dimana kehidupan di penuh kesibukan, memaksa masyarakat memilih untuk melakukan semua hal dengan instan. Permasalahan yang muncul antara lain adalah tidak adanya kehidupan bersosialisasi dan pola hidup yang kurang mendukung kualitas kesehatan masyarakat. Menurut sebuah survey Perusahaan Zipjet (2017), Jakarta masuk dalam kategori kota paling stres dan berdampak pada kemerosotan kesehatan serta kualitas hidup. Open Architecture adalah sebuah proposal arsitektur yang membahasa mengenai The Third place atau ruang antara yang diharapkan mampu melayani kebutuhan masyarakat kota modern. Pluit, Jakarta Utara salah satu daerah yang memiliki karakter third place. Lokasi yang berbatasan langsung dengan first place dan second place di PLuit ini menjadi salah satu alasan pemilihan tapak, Sehingga menghadirkan proyek third place disini diharapkan menjadi solusi permasalahan kawasan. Proyek yang memberi wadah bagi masyarakat untuk bisa datang menghibur diri sejenak dari kesibukan atau masalah yang di hadapinya. Mengutamakan program olahraga dengan maksud meningkatkan minat terhadap kesehatan, dengan konsep wellness yang di sesuaikan juga dengan kebutuhan masyarakat sekitar. Sehingga proyek ini menjadi sebuah tempat pelepas penat yang sekaligus mendukung peningkatan kualitas hidup. Dengan adanya olahraga, sebuah kegiatan yang dalam perkembanganya dapat dilakukan sebagai kegiatan yang menghibur dan menyenangkan, individu antar individu juga dapat bertemu dan memiliki motivasi yang sama sehingga dapat pula tercipta sebuah komunitas yang semakin mempererat kehidupan sosial antar masyarakat sekitar.
\end{abstract}

\section{Kata kunci : hiburan; kesehatan; olahraga; third place}

\begin{abstract}
Urban where life is full of busyness, forcing people to choose to do everything instantly. Problems that arise include the absence of a social life and lifestyle that does not support the quality of public health. According to a Zipjet Company survey, Jakarta is categorized as the most stressful city and has an impact on deteriorating health and quality of life. Open Architecture is an architectural proposal that discusses The Third place or an intermediate space that is expected to serve the needs of modern urban society. Pluit, North Jakarta one of the areas that has a third place character. The location directly adjacent to the first place and second place in PLuit is one of the reasons for site selection, so presenting a third place project here is expected to be a solution to the regional problem. Projects that provide a platform for the community to be able to come entertain themselves for a moment from the busyness or problems they face. Prioritizing sports programs with the intention of increasing interest in health, with the concept of wellness that is also adjusted to the needs of the surrounding community. So that this project becomes a place of fatigue that also supports the improvement of quality of life. With sports, an activity which in its development can be carried out as an entertaining and enjoyable activity, individuals between individuals can also meet and have the same motivation so that it can also create a community that further strengthens social life among surrounding communities.
\end{abstract}

\section{Keywords: entertainment; healthy; sport; third place}




\section{PENDAHULUAN}

Jakarta sebagai Ibu Kota Indonesia, merupakan pusat perekonomian dan pusat pemerintahan. tingginya tingkat kepadatan penduduk berdampak juga pada gaya hidup masyarakat di kota tersebut. Masyarakat kota di tuntut untuk sibuk bekerja agar bisa bertahan di kehidupan perkotaan sehingga terkadang waktu dihabiskan hanya untuk bekerja. Gaya hidup yang modern, dimana kehidupan di kota yang penuh dengan kesibukan memaksa masyarakat memilih untuk melakukan semua hal serba cepat. Permasalahan yang muncul diantaranya adalah kurangnya waktu bersosialisasi dan beraktifitas fisik

Orang mulai mencari hiburan atau tempat berkumpul di pusat perbelanjaan (Mall) yang sebenarnya kurang tepat untuk menjadi tempat bersosialisasi, dimana didalamnya tidak ada interaksi antar sesama. Masyarakat lebih sering berinteraksi dengan sesama hanya melalui handphone atau komputer, sehingga kehidupan bersosial mulai kehilangan makna. Hilangnya interkasi secara langsung antar sesama individu, membuat manusia mulai hidup secara indiviualis, oleh karna itu masyarakat membutuhkan sebuah tempat dimana mereka dapat melepas penat dan berinteraksi dengan sesama.

Kesehatan adalah salah satu hal berharga bagi setiap orang, karena kesehatan adalah sumber kebahagiaan umat manusia. Selain mengkonsumsi makanan sehat, salah satu cara menjalanakan gaya hidup sehat yaitu berolahraga, dengan berolahraga kita dapat meningkatkan kebugaran, vitalitas dan daya tahan tubuh. Kegiatan ini dalam perkembanganya dapat dilakaukan sebagai kegiatan yang menghibur, menyenangkan atau juga dilakukan dengan tujuan untuk meningkatkan kesehatan fisik. Dengan adanya olahraga individu antar individu dapat bertemu dan memiliki motivasi yang sama sehingga dapat pula tercipta sebuah komunitas yang mendukung kehidupan masyarakat kota yang lebih sehat.

\section{KAJIAN LITERATUR}

\section{Open Architecture}

Open architecture adalah sebuah sistem terbuka yang mampu beradaptasi dengan kepentingan terpilih dan menjadi kesempatan untuk menciptakan sebuah platform arsitektur yang dapat dikombinasikan dengan berbagai macam keadaan dan kondisi masyarakat dalam hal ini masyarakat perkotaan Jakarta atau kota besar lainnya.

Open Architecture membahasa mengenai The Third place didalamnya menjelaskan mengenai sebuah program yang di dukung dengan program-program lain yang mampu melayani kebutuhan masyarakat kota modern yang menuntut kehidupan serba cepat, dinamis, dan efisien, sehingga masyarakat kota lebih bersifat humanis dan produktif. Open Architecture merupakan the third place bagi masyarakat kota, yang berfungsi sebagai ruang antara seperti ruang yang bukan tempat tinggal dan bukan tempat kerja atau sekolahan.

\section{Third place (Ray Oldenburg)}

Konsep Third place yang dikemukakan oleh Oldenburg (1999) adalah pembentuk ruang interaksi sosial. Pengertian dari Third place adalah suatu tempat yang bisa dijadikan tempat berlindung sementara dari kebosanan. Pada Third place masyarakat dapat melarikan diri dari First Place (rumah) dan Second Place (tempat kerja) untuk membuka jati diri dan bersosialisasi, dimana semua orang dapat datang kesana dengan berbagai aktifitas.

Dalam konteks masyarakat kota The Third place telah kehilangan makna. Masyarakat kota mencari hiburan, tempat kumpul di pusat perbelanjaan (Mall) dimana didalamnya tidak ada interaksi antar sesama manusia. Berdasarkan penelitiannya, Oldenburg (1999) mengungkap 8 (delapan) karakter yang membentuk Third place yaitu on neutral ground, leveler, conversation is the main activity, accessibility and accomodation, the regulars, low profile, mood is playful, dan a home away from home. 


\section{Wellness}

Menurut ahli dari Universitas Indonesia, dalam sebuah buku "Mind and Body Wellness", bahwa Wellness diartikan sebagai keseluruhan proses menjaga atau mencapai kondisi sehat yang menyeluruh secara fisik, mental, dan emosional. Di sisi lain, definisi dari health berdasarkan KBBI adalah baik seluruh badan serta bagian-bagiannya bebas dari sakit. ${ }^{1}$ Terdapat Enam aspek yang termasuk dalam kategori wellness yang dikembangkan oleh Co-Founder dari The National Wellness Institute, by Dr. Bill Hettle.

\section{Occupational}

Memilih karir yang sejalan dengan minat dan nilai-nilai yang secara pribadi anda yakini. Physical

Physical wellness dapat dicapai dengan cara melakukan aktivitas fisik secara rutin untuk menjaga daya tahan tubuh, dengan mengonsumsi makanan dan minuman yang baik bagi kesehatan Anda, setidaknya 80\% dari total keseluruhan pangan yang Anda konsumsi sehariharinya.

Social

Hiduplah dalam harmoni dengan sesama dan lingkungan dan sebaiknya jangan terjun ke dalam konflik dengan keduanya jika anda ingin mencapai social wellness. Jangan lupa juga untuk berkontribusi dalam kegiatan komunitas sekitar yang bersifat positif.

Intelectual

Akan lebih baik apabila kita sebagai manusia menantang diri sendiri untuk terus menambah ilmu dan mengasah kemampuan yang sudah dimiliki. Hal ini lebih baik daripada kita berpuas diri akan apa yang sudah dimiliki. Intelectual wellness juga berkaitan dengan bagaimana Anda mengidentifikasi masalah dan memilih jalan terbaik sebagai penyelesaiannya.

Spiritual

Aspek atau dimensi yang satu ini dapat tercapai apabila Anda membuka mata dan pikiran akan hidup yang Anda jalani. Jadilah terbuka dan milikilah toleransi terhadap pemikiran dan hal-hal yang menjadi kepercayaan orang lain. Akan tetapi, bersikaplah secara konsisten dalam memegang nilai-nilai yang Anda percayai.

Emotional

Inti dari emotional Wellness adalah sikap hidup yang positif dan optimis. Anda bisa mencapainya dengan peka terhadap kata hati Anda sendiri dan bersikap optimis dalam menjalani hidup.

\section{Aktifitas Fisik}

Setiap orang melakukan aktifitas fisik antara individu satu dengan yang lain tergantung gaya hidup perorangan dan faktor lainnya..Olahraga adalah sebuah gerak badan untuk menguatkan dan menyehatkan tubuh ${ }^{2}$. Olahraga merupakan suatu aktifitas yang sangat erat hubungan nya dengan kesehatan dan kebugaran tubuh, secara umum olahraga didefinisikan sebagai salah satu aktifitas fisik.

Olahraga adalah sebuah aktifitas fisik yang dapat di lakukan secara individu maupun kelompok. Menurut sosiolog olahraga, olahraga dapat menjadi sarana bersosialisasi bagi semua kalangan umur. ${ }^{3}$

\footnotetext{
${ }^{1}$ https://livinghealthylife101.wordpress.com/2015/10/05/apa-itu-wellness/

${ }^{2}$ https://kbbi.web.id/olahraga

${ }^{3}$ https://www.kompasiana.com/meistra/5dd27c60097f364cf54bd612/review-artikel-sport-andsociety?page=all
} 


\section{METODE}

\section{Metode Perancangan Konvensional}

Metode perancangan yang dipakai dalam proyek adalah metode konvensional yang meliputi pengumpulan data (input), analisis (proses), sintesis (output). Dalam merancang sebuah arsitektur, data dan fakta merupakan hal yang menjadi sumber atau dasar ide dalam perancangan. Berdasarkan sumbernya, data dibagi menjadi dua yaitu data primer dan sekunder. Menurut Marzuki (2002:55), data primer adalah data yang diperoleh langsung dari sumber yang diamati, sedangkan data sekunder menurut Umi Narimawati (2008:94) adalah data yang didapat dari sumber yang sudah tersedia.

\section{Pengumpulan data}

\section{A. Data Primer}

Data yang di dapat dari hasil observasi kawasan dan karakter masyarat serta dokumentasi berupa foto untuk di jadikan dasar melakukan Analisa tapak pada kawasan Pluit, Jakarta Utara. Data ini diantaranya mengenai kondisis bangunan sekitar tapak, ketinggian bangunan, fungsi bangunan, peraturan hingga fasilitas umum di sekitar tapak pembangunan dengan radius kurang lebih satu kilometer.

\section{B. Data Sekunder}

Data yang di dapat dari studi pustaka atau literatur mengenai proyek terkait data tentang kawasan dan tapak terpilih, dan studi komparasi untuk mendapatkan data mengenai bangunan yang sejenis. Data ini diantaranya berupa kajian literatur baik dari metode hingga pemahaman mengenai fungsi proyek yang berkaitan dengan aktifitas fisik dan asupan makanan. Terdapat juga data yang di jadikan refrensi untuk mendesain berupa studi kasus bangunan olahraga, bangunan agrikultur, dan ruang komunal masyarakat.

\section{Analisis Data}

A. Analisis makro (Kawasan)

B. Analisis Mezo (Kecamatan-Kelurahan)

C. Analisa Mikro (Tapak)

\section{Sintesis}

Tahap pengolahan hasil analisis menjadi sebuah proses perancangan atau desain. Tahap ini adalah tahap dimana hasil olahan data yang di kumpulkan baik data survey lapangan hingga data literatur (studi presedent) dan di sajikan berupa design bangunan yang menjawab kebutuhan masyarakat di kawasan Pluit, berupa ruang keburgaran. Bangunan yang di harapkan juga menjadi tempat bersosialisasi bagi semua kalangan masyarakat sekitar. 


\section{DISKUSI DAN HASIL}

\section{Pemilihan Lokasi}

Membahas mengenai kebutuhan Thrid Place di Kota khususnya di jakarta, mengenai permasalahan kehidupan perkotaan, dengan menginvestigasi titik-titik dimana terdapat First Place \& Second Place di Jakarta hingga di kerucutkan mencapai cakupan kelurahan. Menginvestigasi bagaimana kebutuhan sebuah Third place dengan skala lingkungan di sebuah kawasan di lihat dari kebutuhan masyarakatnya dalam sudut padang arsitektur. Setelah mendapat hasil investigasi, data tersebut di olah menjadi sebuah design yang menjawab kebutuhan masyrakat sekitar. Mulai dari bagaimana masyrakat dapat mengakses masuk kebangunan, hingga bagaimana bentuk bangunan tercipta.
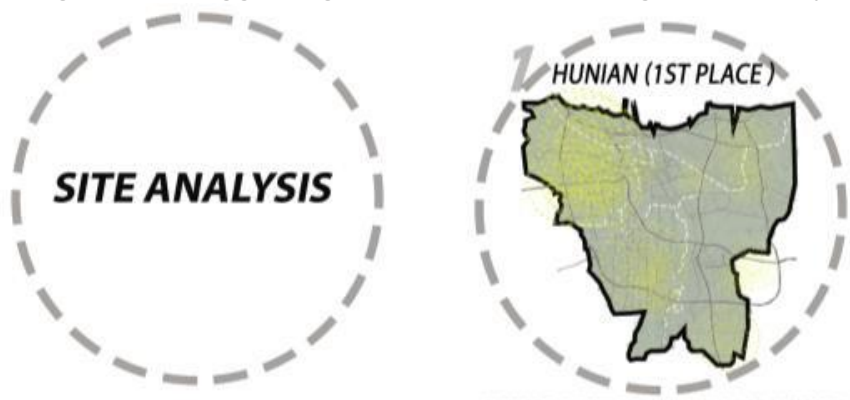

PEMETAAN WILAYAH HUNIAN DI JAKARTA

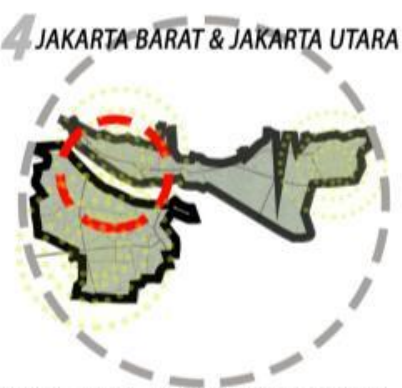

JAKARTA UTARA \& JAKARTA BARAT MEMILK PERTEMUAN WILAYAH HUNIAN DAN TEMPAT BEKERJA YANG MEMILIKI INTENSITAS YANG TINGGI

SUPER-IMPOSED ANTARA 1ST PLACE DAN 2N PLACE MENJADI TITIK PERTEMUAN ANTARA

SALAH SATU KRITERIA 3RD PLACE, BERADA DI TITIK PERTEMUAN 1ST \& 2ND PLACE SEHINGGA MENUNJANG KEHIDUPAN MASYARAKAT

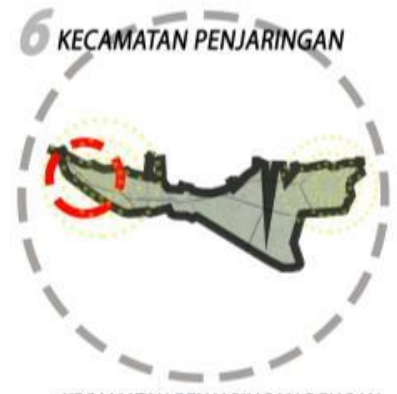

KECAMATAN PENJARINGAN DENGAN KEPADATAN PENDUDUK JUGA MEMILIKI KEBERAGAMAN MASYARAKAT BAIKDAR PERBEDAAN KEBUADAYAAN ATAUPUN EKONOMI. SEHINGGA 3RD PLACE DAPAT MENJADI TITIK TEMU ANTARA BERBAGA GOLONGAN MASYARAKAT.

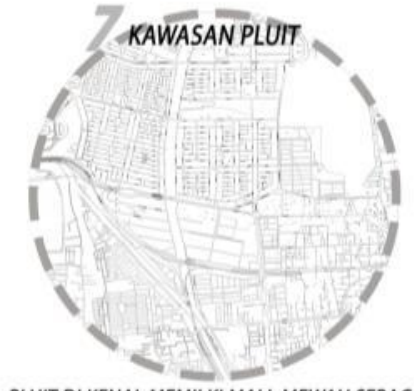
TEMPAT MELEPAS PENAT KEHIDUPAN BELUM TEPAT MENJADI SOLUSI 3RD PLACE DI
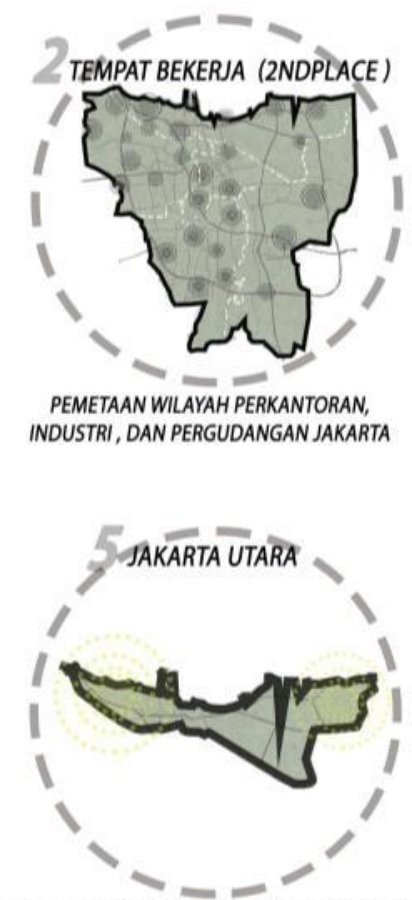

JAKARTA UTARA MEMILIKI KEPADATAN MASYARKAT YANG TINGGI NAMUN TIDAK BERBANDING LURUS DENGAN INDEKS PEMBANGUNAN MANUSIA -NYA. SEHINGGA 3RD PLACE DI WILAYAH INI DAPAT MENJADI USAHA UNTUK MEMBERIKAN PENUNJANG UNTUK POLA KEHIDUPAN MASYARAKAT DIDALAMNYA

PLUIT DI KENAL MEMILKI MALL MEWAH SEBAGAI

PERKOTAAN. NAMUN, MALL MASIH DIANGGAP DAERAH INI. WADUK PLUIT ADALAH SALAH SATU 3RD PLACE YANG MULAI DI KEMBANGKA OLEH PEMERINTAH SEBAGAI AREA REKREASI BERTEMA HIDUP SEHAT

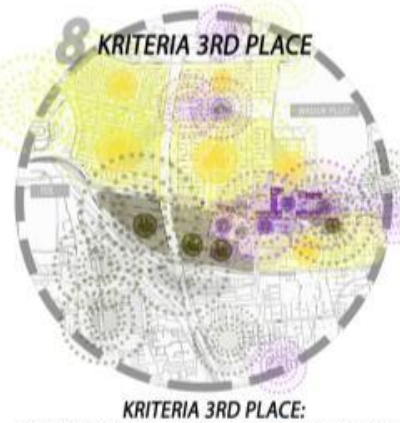

-BERADA DI TITIK PERTEMUAN 1ST \& 2ND PLACE SEHINGGA MENUNJANG KEHIDUPAN MASYARAKAT BERADA DILINTASAN UTAMA ORANG BERPERGIAN - CIRI KAWASAN DAN MASYARAKAT HETEROGEN, DAPAT MENJADI PERTEMUAN

Gambar 1. Analisa Makro Sumber: Penulis, 2019 


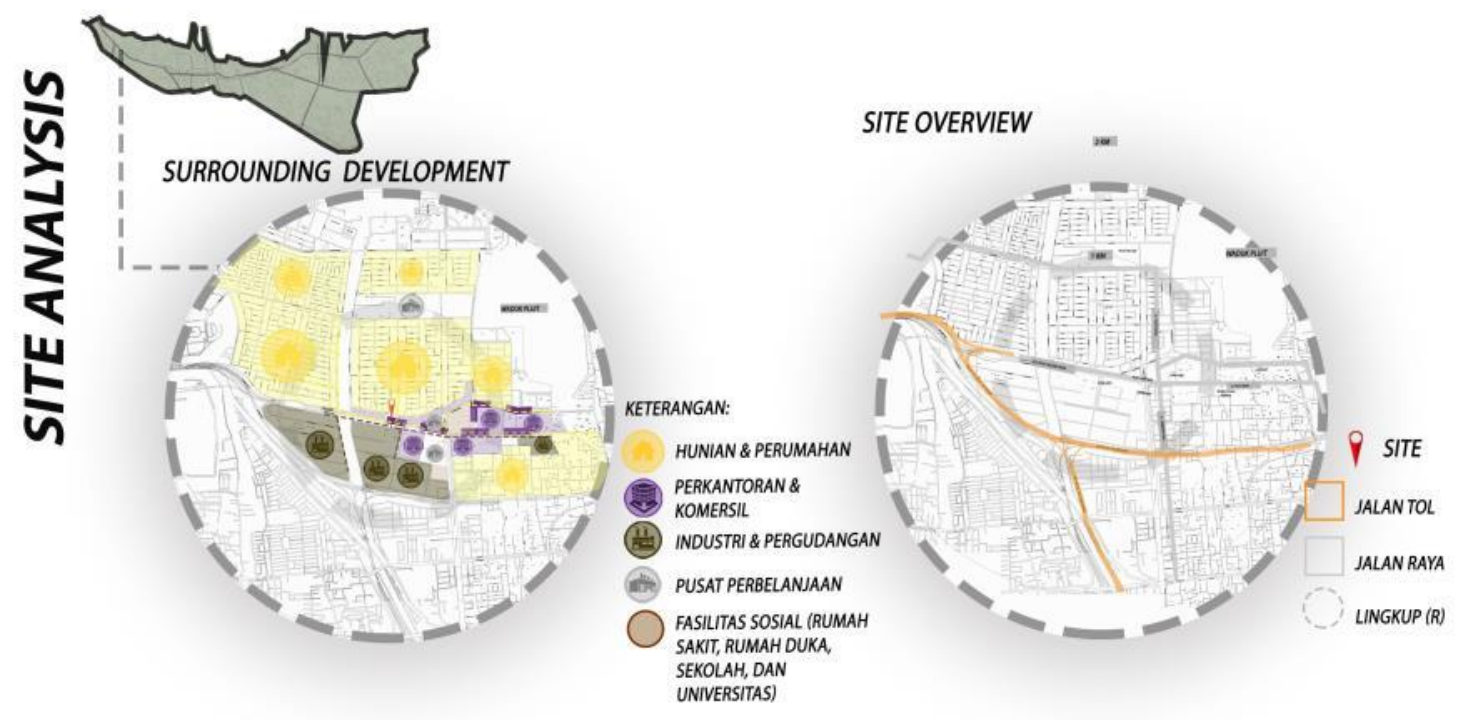

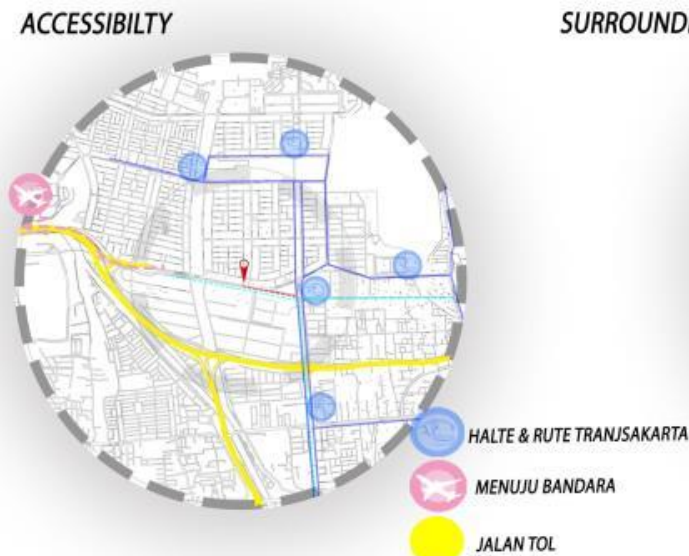

JALANTOL

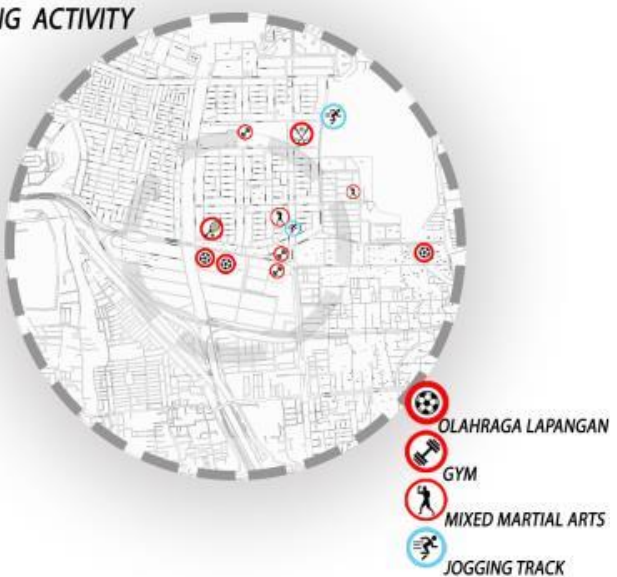

SURROUNDING ACTIVITY
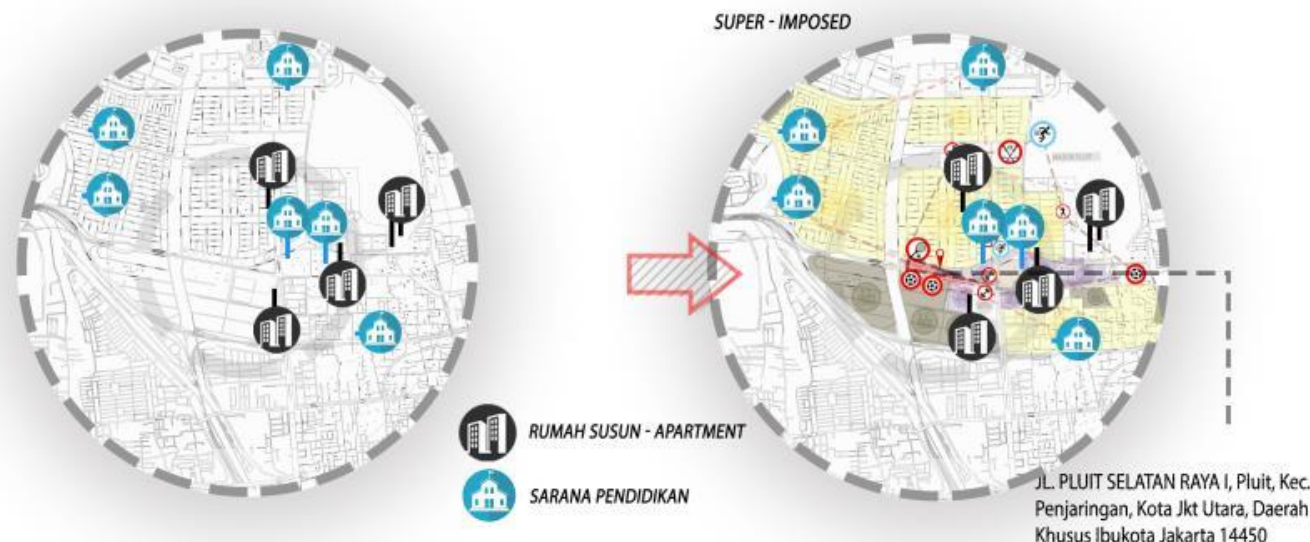

Gambar 2. Analisa Mezzo

Sumber: Penulis, 2019 

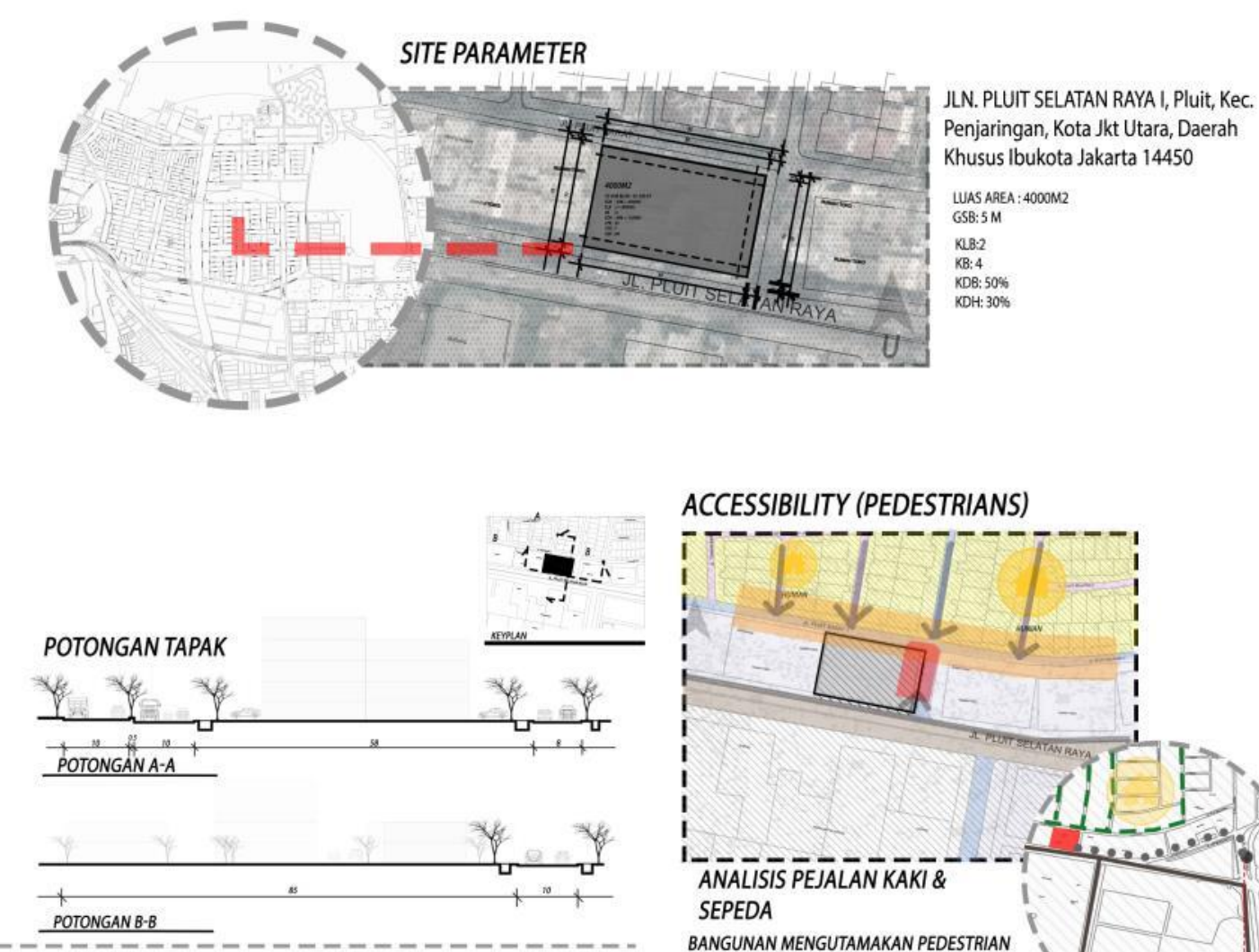

ACCESSIBILITY (PEDESTRIANS)

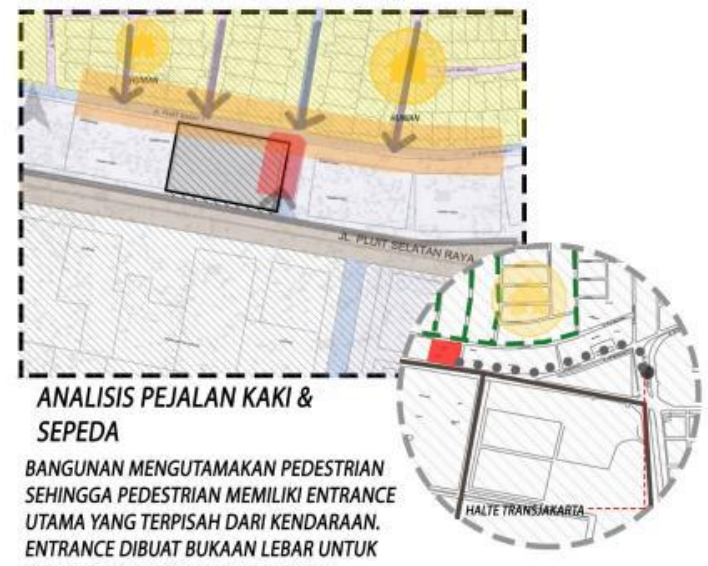

ACCESSIBILITY (IN-OUT) SITE ANALYSIS

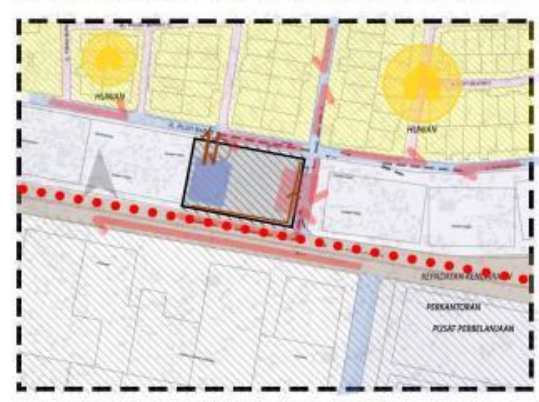

ANALISIS KENDARAN BERMOTOR

KENDARAAN MASUK-KELUAR KEDALAM TAPAK MELALUI SISI BELAKANG BANGUNAN

BANGUNAN MENGUTAMAKAN PEDESTRIAN SEHINGGA MEMBERIKAN BUKAAN DI SISI YANG MENGARAH KEPADA KEPADATAN HUNIAN, PERKANTORAN, DAN MALL

DROP OFF DILETAKAN DISISI BERTANDA MERAH, UNTUK

MEMUDAHKAN KENDARAAN DARI BERBAGAI SISI. KARENA SISI JALAN RAYA MERUPAKAN JALAN SATU ARAH

Penjaringan, Kota Jkt Utara, Daerah

LUAS AREA : $4000 \mathrm{M} 2$

Gambar 3. Analisis Mikro

Sumber: Penulis, 2019 


\section{Konsep Proyek}

Hasil akhir sebuah design bertema Wellness yang di tuangkan dalam bentuk desain bangunan. Bangunan yang di usulkan menjadi sebuah wadah untuk masyrakat mengolah pola hidup sehatnya baik secara kasat mata yaitu fisik dan memalui pola makan yang sehat. Bangunan diharapkan dapat menjawab kebutuhan masyarakat, yaitu tidak hanya sekedar tempat olahraga tapi menjadi ruang komunal bagi masyakarat sekitar, sehingga tercipta komunitas baru yang lebih sehat dan bersosialisasi.

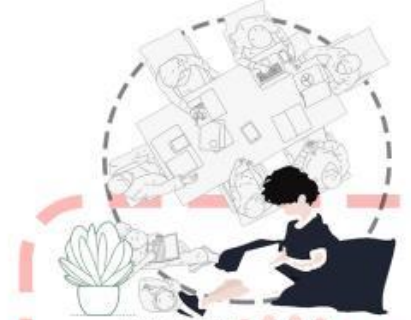

INTELECTUAL

menambah ilmu dan mengasah kemampuan yang sudah dimiliki. Hal ini lebih baik daripada kita berpuas diri akan apa yang sudah dimiliki. Intelectual wellness juga berkaitan dengan bagaimana Anda mengidentifikasi masalah dan memilih jalan terbaik sebagai penyelesaiannya.

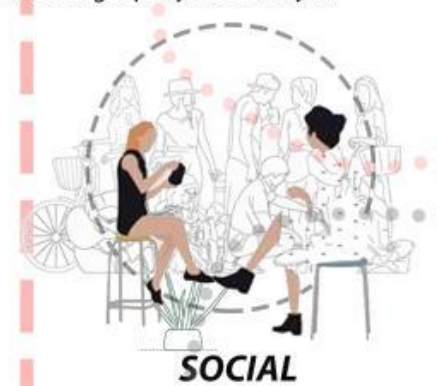

Hiduplah dalam harmoni dengan sesama dan lingkungan dan sebaiknya jangan terjun ke dalam konflik dengan keduanya jika anda ingin mencapai social wellness. Jangan lupa juga untuk berkontribusi dalam kegiatan komunitas sekitar yang bersifat positif.

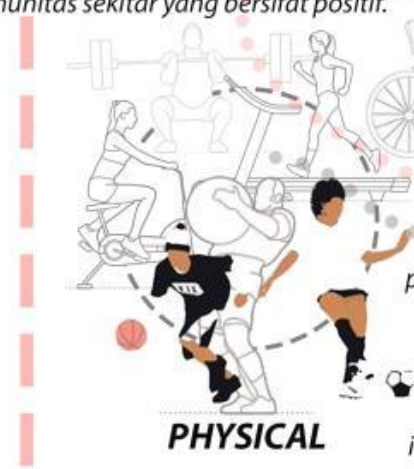

Physical wellness dapat dicapai dengan cara daya tahan tubuh. Selain itu, mengonsumsi makanan dan minuman yang baik bagi kesehatan Anda, setidaknya $80 \%$ dari total keseluruhan

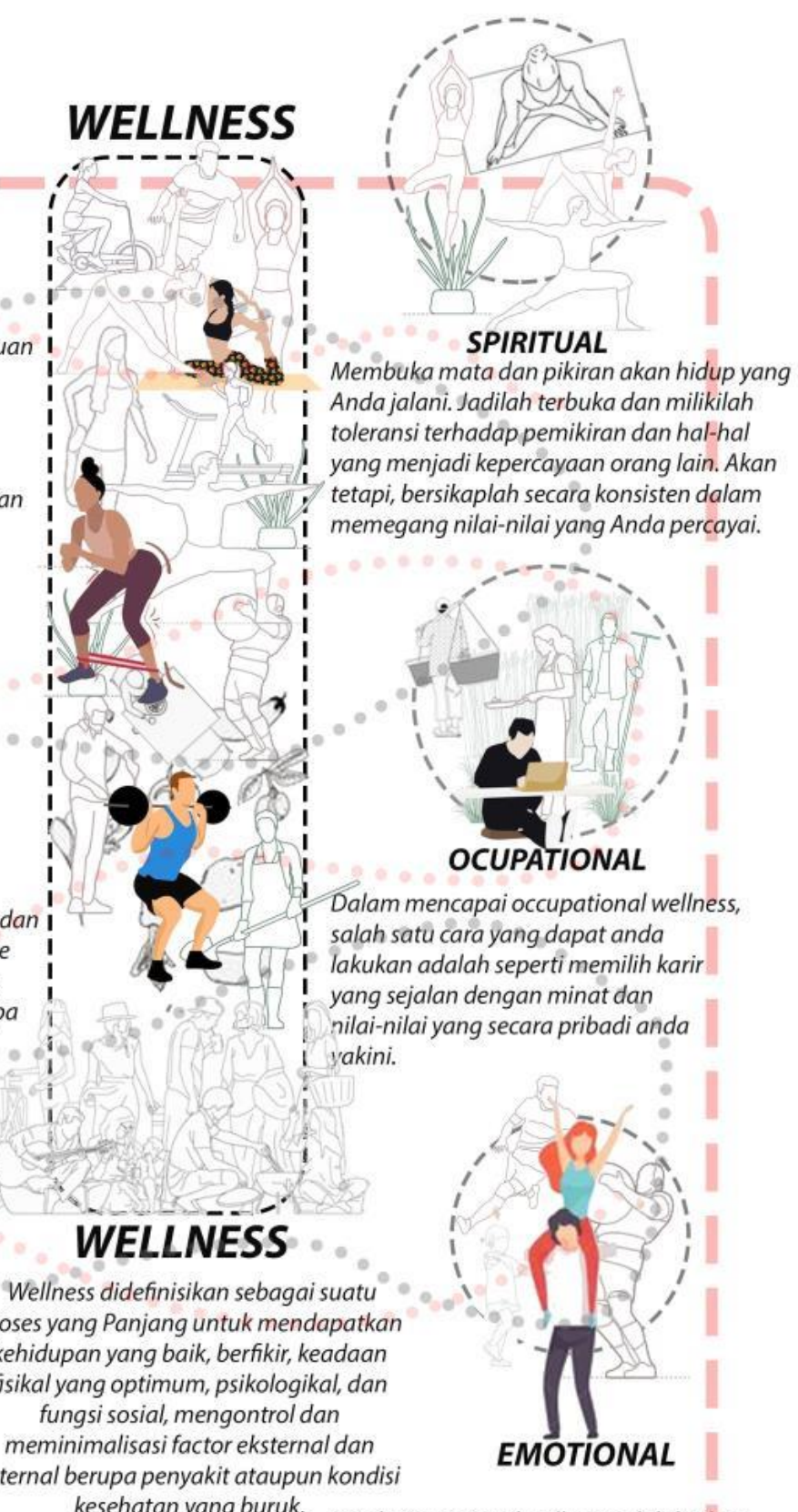
kesehatan yang buruk.

Inti dari emotional wellness adalah sikap hidup yang positif dan optimis. Anda bisa mencapainya dengan peka terhadap kata hati Anda sendiri dan bersikap optimis dalam menjalani hidup.

Gambar 4. Konsep Wellness

Sumber: Penulis, 2019 


\section{Program}

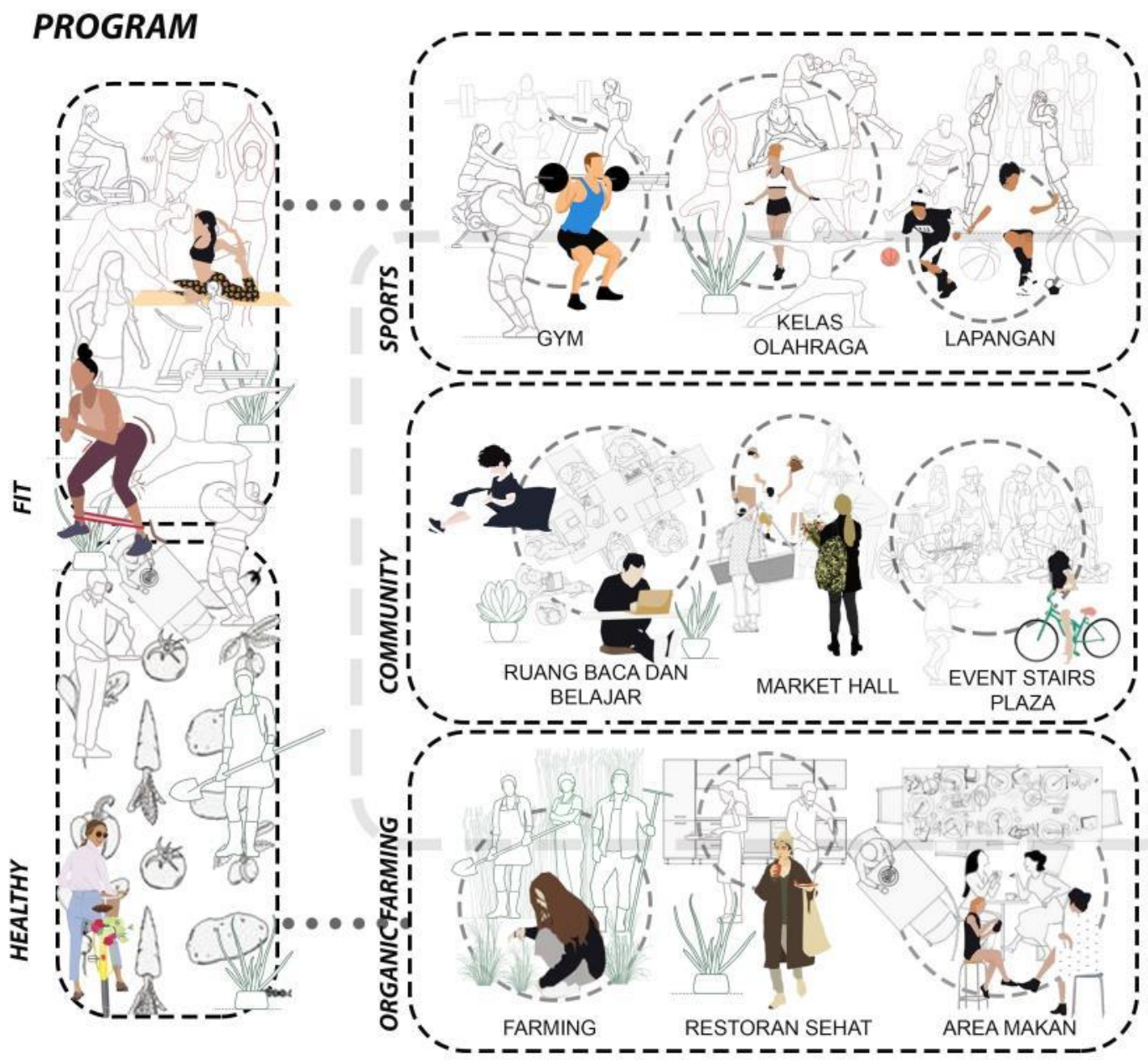

PROGRAM RUANG

\section{SPORTS $35 \%$}

\section{GYM}

KELAS AEROBIC KELAS MARTIAL ARTS LAPANGAN

CALESTENIC

RUANG GANTI

\section{ORGANIC FARMING 17\%}

AREA TANAM (URBAN FARMING) RUANG PENYIMPANAN RUANG PANEN RESTORAN SEHAT AREA MAKAN

\section{COMMUNITY $25 \%$}

RUANG BACA DAN BELAJAR BERSAMA OPEN KITCHEN MARKET HALL

EVENT STAIRS \& PLAZA

\section{PENUNJANG $6 \%$}

RETAIL MAKANAN \& MINUMAN COFFEE SHOPS RETAIL KEBUTUHAN OLAHRAGA

SERVICE $17 \%$

AREA SERVICE -LOADING TOILET

MUSHOLLA

PARKIR

MEP

GUDANG PENYIMPANAN

Gambar 5. Program

Sumber: Penulis, 2019 


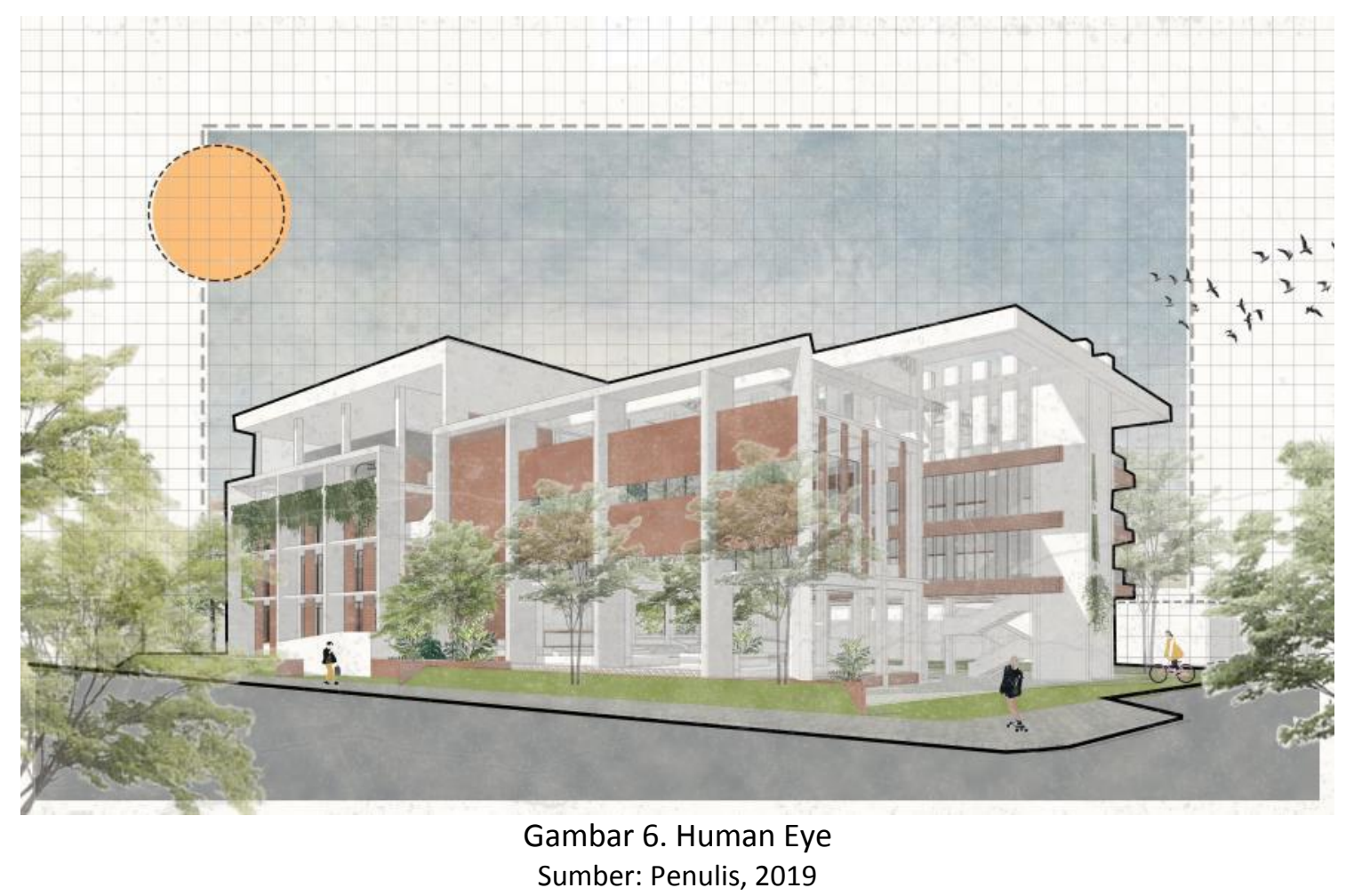

\section{KESIMPULAN DAN SARAN}

Permasalahan yang muncul dalam kehidupan perkotaan adalah kecenderungan masyarakat bersosialisasi pada ruang-ruang komersial dan kurang nya kehidupan bersosialisasi di ruang publik sehingga kehidupan menjadi mahal karena orang rela menghabiskan banyak uang demi bersosialisasi.

Menganalisa lokasi yang cocok untuk menghadirkan third place di perkotaan dengan kepadatan penduduk yang tinggi. Lokasi di Penjaringan, Jakarta Utara menjadi lokasi terpilih yang memiliki karakter lokasi dekat dari first place dan second place. First place pada kawasan ini berupa kompleks perumahan hingga rumah susun atau apartement. Sedangkan second place berupa pergudangangan, perkantoran, hingga sarana pendidikan. Melihat kondisi yang ada, terdapat permasalah berupa kurangnya sarana yang mendukung orang berinteraksi. Masalah kurangnya sarana olahraga di sekitar hunian memperburuk pola hidup masyarakat yang menjadikannya area yang kurang mendukung kesehatan.

Sehingga untuk mengatasi permasalahan yang ada, hadirnya "Third place" diharapkan mampu memberikan solusi dengan menawarkan program berupa area beraktifitas fisik, area berinteraksi, atau sebuah tempat dengan progam yang mendukung gaya hidup sehat dari masyarakat. Proyek berupa sarana olahraga hingga agrikultur diharapkan menjadi sebuah wadah bagi masyarakat berkumpul untuk berinteraksi dengan sesamanya. Menarik masyarakat dari kawasan Penjaringan yang heterogen baik dari sisi ekonomi maupun etnis yang tinggal dan bekerja di kawasan ini. Sehingga kawasan ini mampu mendukung sumber daya manusia yang baik karena proyek yang di harapkan dapat meningkatkan kesadaran masyarkat untuk hidup sehat.

Kehidupan masyarakat yang sehat akan mendukung produktivitas masyarakat itu sendiri yang dapat berdampak pada penilaian sebuah kota-nasional atau sejalan dengan Sustainable Development Goals, diantaranya terdapat good health and well being, quality education, gender equality, and sustainable and communities. 


\section{REFERENSI}

Oldenburg, R. (1989). The Great Good Place. USA: DaCapo Press

Tjahjono, G. (2000). Metode Perancangan Suatu Pengantar untuk Arsitek dan Perancang.

Depok: Universitas Indonesia.

Definisimenurutparaahli.com. Pengertian aktifitas fisik. Di akses pada 01 agustus 2019,dari http://www.definisimenurutparaahli.com/pengertian-aktivitas-fisik/

jakutkota.bps.go.id. 2017. Data kependudukan di Jakarta Utara. Di akses pada 29 Juli 2019, dari https://jakutkota.bps.go.id/

kompasiana.com. Artikel. Olahraga dan Masyarakat dalam Pandangan Sosiologi. Di akses pada 30 Juli 2019, dari

https://www.kompasiana.com/meistra/5dd27c60097f364cf54bd612/review-artikel-sportand-society?page=all

livinghealthylife101.wordpress.com. (2015,05 oktober). Awali Hidup Sehat Dari Hal Kecil.

Diakses pada 01 agustus 2019, dari

https://livinghealthylife101.wordpress.com/2015/10/05/apa-itu-wellness/

Properti.kompas.com. (2017, 30 oktober). Jakarta nomor 18 kota paling stres di dunia. Di akses 02 agustus 2019, dari https://properti.kompas.com/read/2017/10/30/090000621/jakartanomor-18-kota-paling-stres-di-dunia 
